WHAT REALLY COUNTS 



\section{WHAT REALLY \\ COUNTS}

THE CASE FOR A SUSTAINABLE AND EQUITABLE ECONOMY

RONALD COLMAN 




New York Chichester, West Sussex

cup.columbia.edu

Copyright (C) 2021 Ronald Colman

All rights reserved

Library of Congress Cataloging-in-Publication Data

Names: Colman, Ronald, author.

Title: What really counts : the case for a sustainable and equitable economy /

Ronald Colman.

Description: New York : Columbia University Press, [2021] |

Includes bibliographical references and index.

Identifiers: LCCN 2020028956 (print) | LCCN 2020028957 (ebook) |

ISBN 9780231190985 (hardback) | ISBN 9780231549189 (ebook)

Subjects: LCSH: Sustainable development-Government policy. | Economic development_Environmental aspects. | Economic policy. | Equality.

Classification: LCC HC79.E5 C5993 2021 (print) | LCC HC79.E5 (ebook) | DDC $338.9 / 27-\mathrm{dc} 23$

LC record available at https://lccn.loc.gov/2020028956

LC ebook record available at https://lccn.loc.gov/2020028957

Columbia University Press books are printed on permanent and durable acid-free paper.

Printed in the United States of America

Cover design: Milenda Nan Ok Lee

Cover photo: mohamedimages (C) Shutterstock 